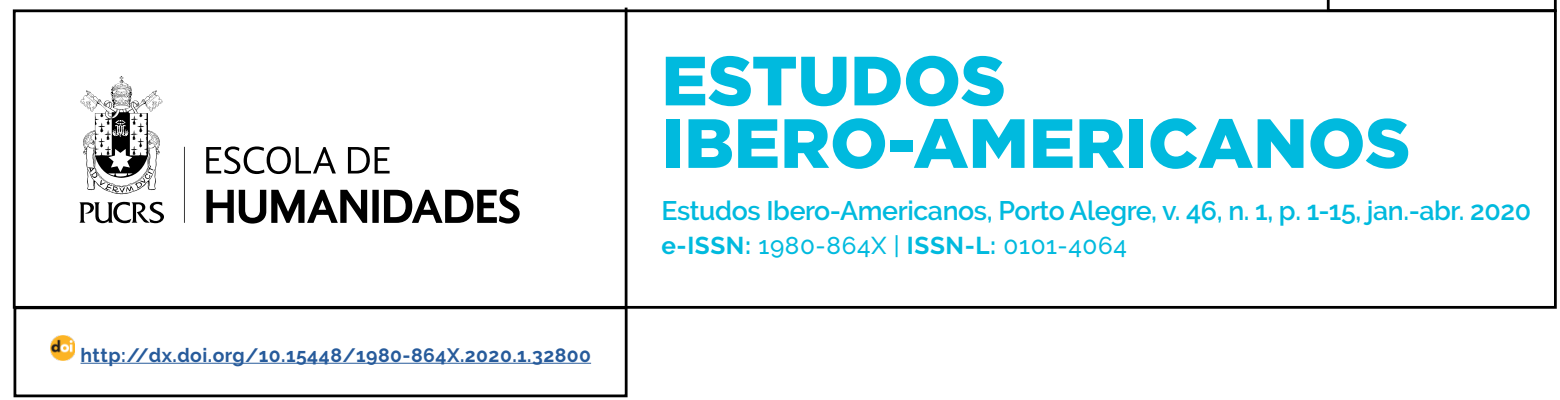

SEÇÃO LIVRE

\title{
Entre el ciudadano republicano y el individuo liberal: el debate sobre el voto obligatorio en el nacimiento de la democracia uruguaya
}

\author{
Between the Liberal Individual and the Republican Citizen: the Debate on the \\ Compulsory Voting in the Birth of Uruguayan Democracy \\ Entre o cidadão republicano e o individuo liberal: o debate sobre o voto obrigatório no \\ nascimento da democracia uruguaia
}

\author{
Javier Gallardo ${ }^{1}$ \\ orcid.org/0000-0001-7958-6814 \\ javiergallardoicp@gmail.com
}

\section{Camilo López Burian' orcid.org/0000-0003-1185-854X camilo.lopez@cienciassociales.} edu.uy

Recebido em: 08 jan. 2019 Aprovado em: 23 abr. 2019 Publicado em: 22 abr. 2020.
Resumen: A la luz del debate sobre el voto obligatorio en la Convención Nacional Constituyente de Uruguay de 1916-1917, este texto reconstruye el ascendiente de un ideario republicano en la política uruguaya, en contrapunto con distintas posiciones liberales. Sin mayores forzamientos semánticos o discursivos, el texto da cuenta de las conexiones existentes entre las posiciones a favor y en contra del voto obligatorio y los leguajes políticos republicanos y liberales que han venido animando gran parte de los debates convencionales sobre la cuestión ciudadana y su reciente reactivación. El artículo permite entrever también la atracción que ejerciera la política de ideas en los debates fundacionales de la democracia uruguaya, así como la relevancia normativa y política de los intercambios deliberativos sostenidos en dicha instancia constitucional.

Palabras clave: Republicanismo. Liberalismo. Ciudadanía. Voto. Uruguay.

Abstract: In the light of the debate on compulsory voting in the National Constituent Convention of Uruguay of 1916-1917, this text reconstructs the ascendancy of a republican ideology in Uruguayan politics, in counterpoint with different liberal positions. Without major semantic or discursive forcings, the text analyzes the existing connections between the positions for and against compulsory voting and the republican and liberal political legacies that have been encouraging much of the conventional debates on the citizen matter and its recent reactivation. The article also allows us to glimpse the attraction that the policy of ideas exerted in the foundational debates of Uruguayan democracy, as well as the normative and political relevance of the deliberative exchanges held in that constitutional body. Key Words: Republicanism. Liberalism. Citizenship. Voting. Uruguay.

Resumo: A luz do debate sobre o voto obrigatório na Convenção Nacional Constituinte do Uruguai de 1916-1917, este texto reconstrói a ascendência de uma ideologia republicana na política uruguaia, em contraponto com diferentes posições liberais. Sem grandes pretensões semânticas ou discursivas, o texto dá conta das conexões existentes entre as posições a favor e contra o voto obrigatório e os legados políticos republicanos e liberais que têm encorajado muito dos debates convencionais sobre a questão do cidadão e sua recente reativação. $O$ artigo também nos permite vislumbrar a atração que a política de idéias exerceu nos debates fundamentais da democracia uruguaia, bem como a relevância normativa e política das trocas deliberativas mantidas nesse corpo constitucional. Palavras chave: Republicanismo. Liberalismo. Cidadania. Voto. Uruguai. 


\section{Introducción}

El relato convencional de la historiografia uruguaya tiende a retratar la politica local como una democracia de partidos, originariamente sustentada en fundamentos liberales e históricamente marcada por diversas composiciones y recomposiciones de un Estado social-benefactor (REAL DE AZÚA, 2000; LANZARO, 2012 y FILGUEIRA, 1994). Recientemente, a partir del giro republicano registrado en la Teoría Política y en el pensamiento historiográfico contemporáneo, tendiente a reconstruir los fundamentos republicanos de la politica moderna o a discutir su validez normativa en los actuales contextos democráticos, han surgido nuevas miradas sobre la matriz fundacional de la política uruguaya y sus estructuras políticas de larga duración, en sintonía con similares lecturas retrospectivas de otras trayectorias políticas de la región. ${ }^{2}$

Estos nuevos tratamientos heuristicos del pasado político nacional, de sus estructuras matriciales y sus itinerarios históricos, han evidenciado la presencia de una fuerte tradición republicana en sus fundamentos constitucionales y en la antesala configuradora de una democracia de partidos, con mayores o menores componentes liberales. Dicha tradición, abonada por la lucha de bandos y de partidos del Uruguay decimonónico, alcanzó una especifica articulación doctrinaria y discursiva entre las élites ilustradas o "doctorales" de fines del siglo XIX y principios del siglo $X X$, particularmente activas en la era posfusionista de la política uruguaya y en la empresa de estructuración normativa del Estado nacional uruguayo. ${ }^{3}$ A su vez, el ideario y discurso republicanos de la política letrada de fines del siglo XIX hicieron sentir su ascendiente en los arreglos políticos e institucionales incorporados a la Constitución de 1917 (GALLARDO, 2001, 2003 y 2018; LÓPEZ BURIAN, 2009) manteniendo su vigencia durante el Primer Batllismo (19031929), tal como lo revelan algunos fundamentos axiológicos de las embrionarias politicas de protección social del Estado "ampliado" uruguayo, entrecruzados de compromisos liberales y democráticos (CAETANO, 2011). ${ }^{4}$

En este texto se reconstruyen dichos alineamientos embrionarios de la política uruguaya, a partir de nuevas miradas teóricas e historiográficas, incursionando en una temática particularmente relevante para el ideario republicano moderno, a saber, la obligatoriedad del sufragio, la cual fuera objeto de singular interés en la política docta de fines del siglo XIX y tratada con particular celo normativo en la Convención Nacional Constituyente de 20162017..$^{5}$ En este ámbito político tuvo lugar, en efecto, una significativa discusión sobre la inclusión del voto obligatorio en el ordenamiento electoral y constitucional del Uruguay. Conforme a una reconstrucción del debate sobre el sufragio obligatorio, desarrollado en las deliberaciones públicas de dicha Convención, este texto incursiona en distintos modelos republicanos y liberales de ciudadanía, estableciendo algunas conexiones teóricas y discursivas entre un conjunto de debates locales y las tradiciones que han venido pautando los debates teóricos de los últimos tiempos en torno a la cuestión de la ciudadanía.

\footnotetext{
2 La nómina convencional de pensadores republicanos incluye a Aristóteles, Cicerón, Maquiavelo, Harrington, Rousseau y los federalistas norteamericanos. La reciente reactivación del republicanismo abarca una amplia literatura teórica e historiográfica. A título indicativo cabe mencionar: Tercheck (1997), Pettit (1999), Pockok (1987), Audier (2004), Brugger (1999). Haakonsen (1995), Ovejero, Marti y Gargarella (2004). Sobre el republicanismo iberoamericano véase Rojas (2009) y Aguilar y Rojas (2002); y para el caso uruguayo consúltese Caetano (2011), Gallardo (2006) y López Burian (2009).

3 La era fusionista de la política uruguaya remite a diversos intentos de unión o disolución de las viejas divisas partidarias durante la segunda mitad del siglo XIX. El posfusionismo refiere, a su vez, al periodo de afianzamiento de la política de partidos tras el ciclo militarista decimonónico. Véase PIVEL DEVOTO, 1994.

4 Bajo la etiqueta batllista o del primer batllismo se designa al ciclo de la política uruguaya fuertemente influido por la figura de José Batlle y Ordoñez, presidente en dos períodos (1903-1907 y 1911-1915) y protagonista de primer orden del Partido Colorado hasta su muerte en 1929.

5 La política docta o letrada, ilustrada o doctoral, abarca un conjunto de actuaciones públicas de diversos núcleos de la intelectualidad política uruguaya, alineados en los partidos tradicionales o envueltos en la fundación de nuevos partidos en las últimas décadas del siglo XIX. Se trata de diversas corrientes políticas catalogadas como "principistas" por sus compromisos doctrinarios y normativos, históricamente contrapuestos a los usos de la politica de caudillos o tradicional. Dichas corrientes desempeñaron importantes roles políticos en diversos foros públicos, en la prensa de ideas y en ámbitos universitarios, en la antesala de conformación de la democracia uruguaya (ODDONE, 1966; GALLARDO, 2001).
} 
Tras explicitar brevemente, en una primera sección, la perspectiva analítica e histórica que preside la reconstrucción de dicho debate, y luego de dar cuenta del marco contextual en el que se desarrollaron los trabajos de los constituyentes, el artículo avanza, en una segunda sección, en torno a una sumaria caracterización de las perspectivas republicanas y liberales de la política y la ciudadanía. En tercer lugar, se abordan los alineamientos republicanos y liberales presentes en los debates constitucionales sobre el voto obligatorio y, finalmente, se incluye una breve conclusión relacionada con las consideraciones efectuadas en las secciones previas.

\section{Ideas y contextos}

Este texto se hace eco, de alguna manera, del giro lingüístico en el pensamiento filosófico y social contemporáneo, tendiente a resaltar la importancia de los usos semánticos y comunicacionales del lenguaje en general, y del lenguaje político en particular. Dicho giro epistémico trajo aparejado un desplazamiento del interés depositado por los estudios clásicos de la Historia de las Ideas o de la Filosofía Política tradicional en las estructuras y trayectorias representacionales o prescriptivas del pensamiento político hacia el discurso y los contextos de enunciación, poniendo en entredicho también la racionalidad autónoma o atemporal de las ideas políticas y las prescripciones normativas.

Con todo, más allá de la importancia política de las prácticas enunciativas y comunicacionales, de su ascendiente en los conceptos y en las ideas políticas, al margen, incluso, de los usos ilocucionarios y perfomativos del lenguaje político, en este texto se traen a consideración las claves semánticas y valorativas de determinados intercambios discursivos, resaltándose su estrecha dependencia de las ideas y convicciones normativas, de suyo expuestas a unajustificabilidad pública y a una racionalidad intersubjetiva. Dicho de otra manera, pese a la indudable relevancia de las recolocaciones y dislocaciones que atraviesan las ideas y valoraciones normativas en diversos contextos lingüisticos o discursivos, ellas no dejan de exponerse a escrutinios reflexivos y criticos, tendientes a abrir o a cerrar diferentes perspectivas de legitimación pública de las cosas políticas.

En consecuencia, el análisis que aquí se realiza de los componentes republicanos y liberales presentes en los discursos a favor y en contra de la obligatoriedad del sufragio en el Uruguay, así como las distinciones avanzadas respecto a distintos modelos de ciudadanía, reflejan una cierta tensión entre pensamiento y lenguaje, entre pretensiones de validez normativa y mediaciones lingüisticas tributarias de un contexto histórico. En otras palabras, en esta indagación retrospectiva se combinan historicidad y discursividad con distintos empeños de justificabilidad y razonabilidad públicas, de donde es posible inferir distintas actualizaciones o conexiones con algunos léxicos y debates teóricos de actualidad. De ahí que en este trabajo no sólo se rinda tributo a una labor de archivo, sensible a un contexto histórico, sino que se privilegien también los alineamientos valorativos y prescriptivos razonablemente homologables a algunas taxonomías y controversias vigentes en la teoría política contemporánea. ${ }^{6}$

A la luz de este enfoque, en el debate uruguayo acerca de la obligatoriedad del sufragio se advierte una variada gama de lenguajes políticos republicanos y liberales, llamados a repartirse el campo de disputas sobre el estatuto y condición de la ciudadanía, según se privilegien distintos componentes institucionales o éticos de las prácticas ciudadanas. A su vez, en estas controversias se aprecia la relevancia histórica de la política de ideas en el Uruguay, en particular, su incidencia en las determinaciones prácticas e institucionales de su vida democrática, así como su ascendiente en los discursos constitutivos de las representaciones y mediaciones simbólicas del mundo político local.

Téngase en cuenta que tales discusiones tuvieron lugar en momentos de reafirmación de una unidad nacional y democrática, cuando aún

\footnotetext{
6 Para una discusión acerca del giro lingüístico y su relación con los trabajos convencionales de la Filosofía Política y la Historia de las Ideas, véase Pocock (1987), Skinner (2007) y Rorty et al. (1990).
} 
se escuchaban los ecos traumáticos de la última guerra civil de 1904 y seguian resonando las viejas querellas decimonónicas en torno al gobierno de partido o de coparticipación (LANZARO, 2003; CAETANO et al., 1987 y CAETANO, 1989). Con todo, las instancias de la Convención Constituyente darán un vuelco fundamental a esos antagonismos históricos, actualizando la tradición del pacto fundacional de 1830, estableciendo los arreglos fundamentales del régimen democrático, así como las bases fundacionales de integración y participación ciudadanas.

Adviértase también que la Convención Constituyente de 1916-17 abrió sus debates sobre el fondo de un fuerte activismo reformista, estatista y de integración social, impulsado por el batllismo gobernante, seguido de diversos "frenos" o movimientos anti-reformistas, originados desde distintas tiendas politicas. Incluso, el tema del voto obligatorio vendrá ligado a prácticas históricas de abstención electoral, convocadas en general por el Partido Nacional, como protesta ante el oficialismo colorado y las falencias de los procesos electorales de la época. De ahi la importancia crucial del debate sobre el sufragio, no sólo por su arraigo en una persistente controversia local, impregnada de distintas dosis de moralidad y estrategia politica, sino también por su estrecha vinculación con el derecho electoral uruguayo, pieza fundamental del proceso de transformación de una política de caudillos tradicionales y de notables doctrinarios en una democracia poliárquica o de partidos.

Desde luego, estos debates no vendrán desprovistos de cálculos prudenciales o de juicios de conveniencia política, sin duda relevantes en las precarias condiciones institucionales de la política uruguaya y en una aún menguada vida democrática. Sin embargo, sus contenidos denotan fuertes valoraciones normativas y éticas, relativamente independientes de las racionalidades estratégicas, de las condiciones históricas de su enunciación o de determinados cálculos de poder. De ahí su posible inteligibilidad como una saga estructurante de lenguajes conceptuales y valorativos de la ciudadanía y la politica uruguaya en su larga duración (CAETANO y RILLA, 2004 y GALLARDO, 2018).

En última instancia, los intercambios de la Convención Nacional Constituyente no sólo ofrecen un corpus discursivo de fuertes rasgos normativos y prescriptivos, sino que permiten avizorar también un momento deliberativo de la política uruguaya, tal como se verá reflejado, por un lado, en los largos e intensos debates entre diferentes voces politicas, envueltas en fuertes asimetrias políticas y provistas de diferentes caudales representativos, y por otro, en la prensa de ideas y en las frecuentes asambleas partidarias de la época. Este activismo discursivo, dicho sea de paso, quizás resulte difícilmente homologable, aunque aqui no vamos a discutir el punto, a algún otro momento de la política uruguaya contemporánea.

\section{Ciudadanía: Liberalismo y republicanismo}

Las ideas y discursos acerca de la ciudadanía contienen diversas transposiciones y dislocaciones históricas y geográficas, modificándose junto con las atribuciones y facultades asignadas a su ejercicio, conforme a los derechos y deberes implicados en sus diversos tratamientos normativos. Así, el concepto de ciudadanía remite al estatuto y condición de los sujetos políticos, a su protección bajo un régimen de derechos, a sus eventuales disposiciones actitudinales y a su involucramiento con las instancias de decisión colectiva. Dicho concepto vendrá informado, a su vez, por diversas controversias sobre su sentido y significación política, dependiendo también de sus alcances éticos o normativos, conforme a diversas contingencias e historicidades, de algún modo replicadas en diversos predicados discursivos y semánticos del término ciudadano.

La modernidad política trajo aparejado una serie de cambios disruptivos respecto a las visiones de la ciudadania de la antigüedad greco-romana y de las repúblicas renacentistas europeas. Si la vida del ciudadano clásico y de la temprana modernidad aparece fuertemente ligada a los destinos de la comunidad política, aunándose las libertades políticas y participativas a los deberes y sacrificios exigidos por la vida común y el auto- 
gobierno de la ciudad, bajo la modernidad liberalrepublicana el ciudadano será visto, o bien como una identidad dependiente de un sujeto anterior a la sociedad y al orden político, convirtiéndose en la instancia última de legitimación, acaso instrumental, de un ordenamiento contractual, o bien como un miembro activo y autónomo de una soberanía política constitucionalmente regulada. Estos modelos históricos se repartirán, de alguna manera, el territorio conceptual y valorativo de la ciudadanía en la modernidad liberal-republicana, ya sea para ajustarla a un orden seguro y protegido de libertades y derechos fundamentales de los individuos, ya sea para elevarla a una política de la virtud y a un activismo civico, disputándose, en suma, la identidad legal y ética del ciudadano.

De ahí que la cuestión de la relación entre la ciudadanía y el ejercicio del sufragio, de suyo intrinsecamente moderna, haya puesto en juego diferentes aspectos juridicos, normativos e identitarios del sujeto ciudadano. A su vez, las distintas teorías modernas de la ciudadanía vendrán a conjugar diversas combinaciones, fundacionales o evaluativas, del acceso a la política y al ejercicio del sufragio, según se privilegie la figura de un individuo protegido en sus derechos y libertades básicas, o bien se prioricen los atributos de un agente participativo y responsable por el ejercicio integro del autogobierno colectivo, sin olvidar, en este sumario inventario taxonómico, las tendencias a enfatizar los vínculos de pertenencia o de arraigo a una comunidad tributaria de una cultura común.

Como veremos en la próxima sección, mientras el liberalismo tiende a priorizar el lenguaje de los derechos, junto a la tutela pública de las autonomías individuales, la tradición republicana enfatiza el valor intrínseco de la participación politica y las obligatoriedades cívicas, al tiempo que las diversas reactualizaciones de las perspectivas comunitaristas subordinan la autonomía y la actividad política de los ciudadanos a sus encarnaciones adscriptivas en entramados societarios y culturales.?

\subsection{La tradición liberal}

En su corriente principal, el liberalismo transmite una actitud de neutralidad entre las distintas doctrinas éticas, perfeccionistas o de vida buena, centrándose en la protección de la independencia y autonomía de los individuos, admitiendo o legitimando las interferencias colectivas que refuercen y no afecten estas últimas De ahí que el liberalismo tienda a focalizarse en el lenguaje de los derechos y cultive un particular celo constitucional por las autonomías individuales, tendiendo a priorizar los derechos del individuo frente a los del ciudadano, delimitando las facultades de este último de modo que no interfieran en los fueros autónomos del primero, trazando fuertes límites entre la esfera pública y privada, entre la sociedad civily el Estado. (MILL, 1970; RAWLS, 2004 y NINO, 2013).

De este modo, desde la perspectiva liberal el ejercicio de los derechos políticos presenta un aspecto facultativo o instrumental, quedando librado a la esfera de la voluntad individual en nombre de la libertad natural o de las libertades negativas, esto es, de no interferencia en el campo de elecciones individuales, dependiendo también del tratamiento neutral de las preferencias de los individuos en el plano cívico. Y si bien la integración universalista de los ciudadanos a la democracia representativa, unido a la división constitucional del poder político, conforman un dispositivo típicamente liberal contra los arrestos compulsivos del Estado o de mayorías soberanas, de todas formas, para la tradición liberal las actuaciones en sedes politicas y ciudadanas deben venir justificadas por sus beneficios a la libertad individual, a los derechos civiles o al bienestar agregado de los ciudadanos individualmente considerados.

En definitiva, frente a las fuertes responsabilidades y obligatoriedades civicas heredadas de la antigua polis y de las repúblicas en pequeño formato, el liberalismo antepone las libertades del individuo y su autonomía para elegir distintas formas de vida, entre ellas,

\footnotetext{
7 Entre los múltiples modelos de ciudadania registrados en la literatura especializada, con énfasis en las categorias utilizadas en este trabajo, pueden consultarse Kymlicka (1996), Miller (1997) y Peña (2003)
} 
las formas de vida no-política. Incluso, del escepticismo epistémico del liberalismo respecto a la racionalidad de las conductas y actuaciones politicas de los cuerpos ciudadanos se desprende un código de virtudes liberales centradas en la autonomía electiva y la responsabilidad de los individuos ante sus propias decisiones, con independencia de las cargas y obligaciones que demande el auto-gobierno colectivo.

\subsection{La ciudadanía republicana}

La tradición republicana no ofrece un canon de textos articulados, sin que por ello deje de ofrecer un conjunto de conceptos y discursos que la diferencian del liberalismo y de otras familias de ideas políticas. Desde sus orígenes en la politeia griega y en la civitas romana, la concepción republicana de la ciudadanía pasó por sucesivas actualizaciones históricas y normativas, siendo reactivada en las fundaciones de las repúblicas dieciochescas en Norteamérica y Francia, así como en las inciertas horas de advenimiento de las democracias representativas, de la política profesional o de los ordenamientos jurídicoburocráticos del Estado-nación. El republicanismo vino así a reafirmar, ante distintas tendencias históricas hacia la división del trabajo político o hacia el "privatismo civil" de los individuos, sus compromisos con el espíritu público, el activismo ciudadano y las libertades políticas o positivas (ARENDT, 1993; HABERMAS, 1998; PETTIT, 1999 y DOMĖNECH, 2003).

Si bien algunas corrientes republicanas asimilarán las prácticas ciudadanas a una ética sacrificial de intereses particulares, reivindicando ideales trascendentes de bien común o de voluntad general, otras priorizarán, a la manera de Maquiavelo, Harrington y los farmers norteamericanos, una distribución institucional del poder de acción común de los ciudadanos. En todo caso, las distintas variantes republicanas comparten una común reivindicación de los bienes y deberes intrínsecos al autogobierno colectivo, privilegiando un ethos cívico inherente al íntegro ejercicio de la soberanía popular. Habida cuenta de la centralidad acordada por el republicanismo al ciudadano y a su poder de acción común, no es de extrañar que sus distintas corrientes le acuerden a la política y a las identidades cívicas un valor preponderante o no instrumental frente a otros intereses e identidades sociales.

A su vez, para la tradición republicana más consustanciada con la centralidad de la política, la participación política y el sufragio adquieren el carácter de investiduras públicas susceptibles de afectar a toda la sociedad, y no sólo a los intereses particulares de los individuos, comportando obligaciones o deberes especiales para con el colectivo social. Desde esta perspectiva, la autonomía de los individuos depende fuertemente del pleno ejercicio de las libertades políticas en el marco de una comunidad auto-gobernada. Incluso, la importancia acordada por el republicanismo a las obligaciones cívicas vendrá acompañada de diversas reminiscencias de la vieja tradición de las milicias y magistraturas ciudadanas. Por diversas vías, entonces, el pensamiento republicano reivindicará el valor intrínseco de la participación política, privilegiando al ciudadano frente al individuo, comprometiéndolo con las responsabilidades cívicas y con diversas actividades de autogobierno, valorando la participación política, no tanto por sus servicios a la conservación o al ejercicio de la libertad individual, sino por su contribución al combate contra la corrupción y la soledad del poder.

A diferencia del liberalismo, en la tradición republicana los derechos individuales no son contemplados como facultades subjetivas independientes de su reconocimiento por parte de las instituciones políticas, ni operan tampoco como "cartas de triunfo" frente a las acciones colectivas, cuya integridad procedimental y sustantiva vendría a depender, en una clave republicana, de la calidad de las deliberaciones o de su capacidad para destilar una genuina voluntad común. De ahí la importancia consagrada por el republicanismo al valor político de la virtud, entendida como una disposición a poner el espíritu público y los intereses generales por encima de los intereses particulares o de los 
equilibrios optimizadores de utilidades fácticas. Las instituciones políticas republicanas vendrian a requerir asi de arreglos que permitan un activo y variado involucramiento del pueblo en los asuntos comunes, cuando no de sustentos educacionales y formativos susceptibles de perfeccionar el carácter civico de los ciudadanos y sus excelencias participativas.

\section{Republicanos y liberales ante el voto obligatorio}

Estas visiones de la ciudadanía estuvieron presentes, de una manera o de otra, en los debates de la Convención Constituyente de 1916-1917, en particular, en las discusiones tendientes a decidir una normativa común en torno al sufragio y al voto obligatorio. ${ }^{8}$ Téngase en cuenta que la discusión sobre el ejercicio del sufragio ocupó un lugar relevante en los discursos de los convencionales, electos para reformar la Constitución fundacional de 1830. Pese a que algún representante propuso no desglosar la discusión sobre el sufragio del tratamiento en conjunto de la carta constitucional, otras voces abogaron por abordar prioritariamente el tema del sufragio, conforme a una tradición nacional fuertemente centrada en la cuestión del voto y en su ordenamiento institucional. Alguna de estas voces, como la del convencional Washington Beltrán, del Partido Nacional, llegó a afirmar, en tal sentido, que "de la manera de reglamentar el sufragio depende la salud ó la muerte de un Estado". (DSHCNC, tomo II, p. 206-207).

El informe que la Comisión de Constitución presentara a la Convención, junto a un proyecto de enmienda y adición a la Constitución vigente, vino a reafirmar la concepción del sufragio como un elemento consustancial al autogobierno colectivo. ${ }^{9}$
Yen la enmienda propuesta se dejaba establecido que todo ciudadano es miembro de la soberanía de la nación, siendo elector y elegible, aunque sujeto a las restricciones -propias de la época- de edad y sexo. La propuesta de la Comisión incluyó la inscripción obligatoria en el Registro Cívico, el voto secreto y la representación proporcional, prohibiéndose el voto a policias y militares

Esta iniciativa constitucional, finalmente aprobada, vino a poner fin al voto público y a la regla mayoritaria, por entonces vigentes en el país. Ya en la discusión general de dicha enmienda se manifestaron distintas visiones sobre la libertad y obligatoriedad del sufragio, algunas de ellas alineadas con visiones republicanas de la ciudadanía, otras de espíritu liberal, y otras recostadas, en fin, en distintos juicios de conveniencia sobre su inclusión en la letra constitucional, insistiéndose en las consecuencias favorables o desfavorables del uso abstencionista del voto.

El debate sobre la obligatoriedad del voto recogió profusos antecedentes históricos y normativos, algunos de ellos protagonizados por los circulos de la ilustración política local, históricamente rotulados como "doctorales" o "principistas", siendo distinguidos asi de la política de caudillos o de los políticos "netos" de las tradiciones históricas del partidismo blanco o colorado. Tras sortear con éxito la política de fusión, los núcleos principistas de la política letrada del último tercio del siglo XIX dieron muestras de una firme adhesión a una "religión republicana", fuertemente imbuida de la política de la virtud y de la tradición del activismo cívico (GALLARDO, 2001). Ya el círculo principista del Partido Colorado, desde las páginas del diario "El Siglo" -dirigido por José Pedro Ramírez-, vino a reivindicar, a principios del último tercio del

8 La Convención Nacional Constituyente estuvo integrada por representantes del Partido Colorado, del Partido Nacional, también llamado Blanco, del Partido Socialista y de la Unión Cívica. Los batllistas, miembros de la fracción colorada que respondía al presidente de la República, concurrieron de forma esporádica a la Convención, sin dejar de ser protagonistas relevantes de sus debates.

9 La Comisión de Constitución dejó así sentado que la Constituyente debía comenzar la reforma "por todo lo que concierne á la manera de garantir el voto libre de los ciudadanos, pues el sufragio constituye la base de la democracia representativa". "Lo primordial -añadia el informe- es asegurar al pueblo la manera de que se gobierne por sí mismo é imponga su designio. Antes de modificar el edificio, hagamos sólidos los cimientos. (...) Garantir el sufragio es la esencia en toda democracia, por organizada que esté, pero se convierte en necesidad imperiosa y dominante cuando se trata de naciones jóvenes como la nuestra, y como medio de extirpar las revoluciones intestinas y decretar la muerte de los gobiernos electores, personales ú oligárquicos. (...) Se debe grabar, pues, en la Constitución, esas garantias primordiales, que aseguran la verdad de la democracia. Sus bienes materiales y morales serán incalculables: daremos á los ciudadanos el medio para que expresen de modo real su voluntad: para que el carácter se perfeccione y el espíritu se ennoblezca y el corazón se haga viril en la práctica incesante del derecho. (DSHCNC, tomo II, p. 159-160). 
siglo XIX, la naturaleza colectiva y pública del voto, extrayendo de estas premisas el imperativo moral y politico de su obligatoriedad:

El sufragio presenta dos caracteres (...): es un derecho político y al mismo tiempo una función pública. Como garantía de los derechos civiles, como expresión de la soberania popular es un derecho politico. Es una función pública en cuanto influye directamente sobre la colectividad y en cuanto su ejercicio es indispensable para la organización del poder público, sin cuya existencia no pueden existir las sociedades. (...) El sufragio, teniendo por fin la organización del poder público, influye directamente en la colectividad; no es uno de esos derechos cuyo ejercicio redunda exclusivamente en provecho o en perjuicio de un individuo; el que lo ejerce tiene que tener en cuenta, no su interés particular como sucede en el caso de los derechos individuales, sino el interés general de la comunidad (....) El sufragio no es un derecho renunciable y los ciudadanos designados para organizar por medio del sufragio el poder público, pueden ser compelidos y obligados a llenar la función que les está encomendada. (...) La organización de la autoridad no es menos necesaria; sin ella la nación desaparece y los vínculos sociales se disuelven: el ciudadano debe ser obligado a ejercer el sufragio. (El Siglo, 30 de agosto de 1872).

Similar reivindicación se advierte en la obra de Justino Jiménez de Aréchaga, primero de un linaje de constitucionalistas uruguayos, especialista en Derecho Electoral y figura de gran ascendiente entre los tratadistas constitucionales locales. En su libro La libertad politica, de 1884, Jiménez de Aréchaga sostuvo:

Mientras que el hombre ejerciendo sus derechos individuales, sólo dirige el desenvolvimiento de su personalidad, sólo afecta de una manera directa sus propios intereses, cuando concurre por medio del sufragio a la formación de los poderes públicos, su acción tiene por exclusivo objeto la dirección de los intereses sociales (...) Entiendo pues, que siendo juridicamente obligatorio para los ciudadanos el ejercicio del sufragio y de toda otra función de soberanía, sería más propio llamar a estas deberes politicos reservando la palabra derecho para designar las libertades individuales. (...) Obligados a mezclarse en el movimiento político de la sociedad, los ciudadanos adquirirán necesariamente esa instrucción política que enseña cuan estrechamente unidos están los intereses públicos con el interés individual y cuán esencial es para el orden y para la prosperidad social el más amplio ejercicio de la libertad política. De modo, pues, que el ejercicio obligado del sufragio por parte de los que al presente se abstienen de votar produciria el efecto de sacarlos de su actual indiferencia de los intereses públicos y de hacerlos comprender las ventajas que aún desde el punto de vista de sus intereses personales reportarian tomando una parte activa en la política, ejerciendo la función electoral. (JIMÉNEZ DE ARÉCHAGA, 1884, p. 6, 29, 35 y 36).

En el debate de la Constituyente de 19161917, las posiciones favorables al voto obligatorio vinieron a reactivar el discurso docto-principista de "El Siglo" y de Jiménez de Aréchaga, en particular, sus fundaciones éticas y sus valoraciones políticas, sin dejar de aludir a algunas experiencias históricas relativas a la obligatoriedad del sufragio y a su inscripción en ordenamientos normativos positivos. El representante nacionalista Luis Gutiérrez, quien tuviera a su cargo la iniciativa de prescribir el sufragio obligatorio en el texto constitucional, se hizo eco de estas posiciones, aventurando que la obligatoriedad del voto imposibilitaría la abstención coaccionada de los ciudadanos (DSHCNC, tomo II, p. 167). Pero la defensa republicana de la obligatoriedad del voto atravesó todo el espectro partidario, desde los convencionales de los partidos tradicionales, Colorado y Blanco, hasta los representantes del Partido Socialista y la Unión Cívica, llamados a ensanchar el arco de la política tradicional blanqui-colorada hacia la política "de ideas" o hacia partidos más ideológicos o doctrinarios.

En su argumentación favorable al voto obligatorio, en línea con los "principistas" decimonónicos, el convencional de la Unión Cívica, Joaquín Secco Illa, tras reivindicar el patriotismo cívico y el activismo político de las "masas populares", sostuvo:

En teoria no es posible discutir ya si el sufragio es un derecho ó es un deber, porque todos reconocen que el sufragio es más que un deber, es una función necesaria en las sociedades que se rigen por el régimen republicano. La obliga- 
toriedad del voto es una conquista que no debemos dejar al margen en esta reforma que introducimos en la constitución, porque será un procedimiento eficaz y seguro para obtener, bajo la garantía simultánea del voto secreto y de la representación proporcional, que esa abstención que tanto daño ha hecho al país, -favoreciendo manejos electorales de gobiernos que olvidan los fueros populares,- desaparezca, haciendo participar, por la exigencia imperiosa de la ley y por la progresiva educación civica de las masas populares, á todas las tendencias y á todas las aspiraciones, en las luchas pacíficas y ennoblecedoras del comicio. (DSHCNC, tomo II, p. 216).

También otro representante de la Unión Civica, Hugo Antuña, abogó por el voto obligatorio, considerando el sufragio "como un deber irrenunciable del ciudadano, y no como un simple derecho del mismo, entendiendo que respondía a "las exigencias normales de la colectividad política." (DSHCNC, tomo II, p. 253-254). A su vez, uno de los más activos convencionales del Partido Nacional, el ya citado Washington Beltrán, asumirá una de las más radicales reivindicaciones de la obligatoriedad del voto, asimilándola a "un deber elemental del ciudadano", ilustrando su validez histórica y normativa mediante referencias a casos nacionales y a tratadistas europeos del Derecho Público favorables a dicha medida. La inscripción del voto obligatorio en los preceptos constitucionales debia inferirse, según Beltrán, de su "doble aspecto jurídico y político" (DSHCNC, tomo II, p. 255), pues el sufragio, a su juicio, no podia equipararse sólo a un derecho sino contemplarse también como una función, como un acto a ser ejercido "en interés de la sociedad". Tras recordar que el Estado podía obligar a los ciudadanos a "intervenir en la ejecución de las leyes", Beltrán se preguntó si "¿no es evidente que la sociedad pueda obligar a los ciudadanos a elegir los cuerpos que han de dictar esas mismas leyes?" (DSHCNC, tomo II, p. 255-256).

Además de asignarle al voto una "alta importancia del punto de vista moral" y de asimilarlo a una "exigencia perentoria del patriotismo", Beltrán consideró que el voto obligatorio debía operar como un incentivo a la participación, recordando que en Europa, antes de la Gran
Guerra de 1914-1918, su implantación positiva procuró contrarrestar la abstención, para hacer frente a grandes núcleos de "egoístas, escépticos, indiferentes y desesperanzados", desentendidos "del acto más vital de la democracia" (DSHCNC, tomo II, p. 256). En su alegato a favor de la obligatoriedad del voto, este convencional sostuvo asimismo que, si bien su prescripción debía surgir "del fondo mismo de las conciencias de los ciudadanos", iba también a "formar la costumbre del voto" en el pueblo (DSHCNC, tomo II, p. 258). Y acudiendo a argumentos jeffersonianos y tocquevillianos, orientados a vincular la participación y el autogobierno con la educación pública y la política municipal, Beltrán le atribuyó a ambas instancias el carácter de sendas fuentes formadoras de ciudadanía:

Para mí, los dos grandes factores coadyuvantes con el voto obligatorio, son la escuela primaria y la escuela del municipio; la escuela primaria difundida por todo el país, por millares de establecimientos, llevada á los extremos más lejanos, inculcando en los niños, desde que su conciencia despierta, el concepto de que deben votar y que los ciudadanos tienen que llenar la función del voto con el espíritu alto y sano como si desempeñara una función sagrada; y la escuela del municipio, educando á los hombres en la práctica del gobierno propio y en la grandeza de la vida libre. (DSHCNC, tomo II, p. 259).

Luis Alberto de Herrera, convencional del Partido Nacional, figura de relieve en las luchas partidistas del Uruguay del siglo $X X$, vio en el voto obligatorio, al igual que Beltrán, una forma de educar a los ciudadanos. En esta dirección, equiparó la obligatoriedad del voto a "una de las garantias más eficaces, más prácticas y más viables que puedan tomarse para fortificar no solamente el sufragio, sino el hábito de votar en el país." (DSHCNC, tomo II, p. 246). Y en actitud consistente con sus persistentes inclinaciones pragmáticas, Herrera procuró dar cuenta de las distintas posiciones en juego, proponiendo que se inscribiera en el texto constitucional el voto obligatorio junto con la representación proporcional, de modo de contentar a quienes ponían énfasis en una u otra prescripción. 
Esta propuesta fue rechazada por varios convencionales, entre ellos. por el socialista Emilio Frugoni, y el nacionalista Enrique Andreoli, quienes puntualizaron la naturaleza diferente de ambas cuestiones. En su defensa de la inclusión del voto obligatorio en la Constitución, Frugoni esbozó un modelo de ciudadanía activa, centrado en un ideal de autogobierno y en el involucramiento en los individuos con los asuntos públicos. Fundador y por entonces dirigente emblemático del Partido Socialista, con representación legislativa desde 1910, Frugoni identificó al voto con una función pública, sosteniendo que "todos los ciudadanos de una República democrática tienen la obligación moral de contribuir a la formación de sus autoridades... (...) de intervenir con su voto en la solución de todos los problemas que afectan la suerte presente y futura de la colectividad. (DSHCNC, tomo II, p.265-267). También Celestino Mibelli, otro convencional socialista, se sirvió de un ideario republicano para argumentar que el sufragio vendría a operar como una forma de educar a la ciudadanía en la cultura del deber civico.

En suma, para estas posiciones, consustanciadas con las más clásicas visiones republicanas del ciudadano y la vida cívica, el voto no es catalogado como un derecho que los individuos ejercen de manera voluntaria o facultativa, ni como un medio de maximizar utilidades o intereses individuales. Antes bien, la participación política y electoral es vista como un deber moral y como una instancia consustancial a la formación de una voluntad común con efectos vinculantes sobre toda la sociedad. Desde esta perspectiva, el voto es valorizado también como un elemento formador de un ethos civico y de una cultura participativa, necesaria para combatir una displicente actitud abstencionista y fortalecer la autoridad legítima de las actuaciones democráticas.

Los alineamientos favorables a la obligatoriedad del voto despertaron diversos cuestionamientos y reacciones criticas entre distintas representaciones de la Asamblea Constituyente, trayendo a colación argumentos que fueran ya expuestos de algún modo en el debate del doctoralismo decimonónico sobre este punto. Algunas posiciones críticas vendrán fundadas en una moralidad liberal, otras invocarán razones de prudencia politica, sin que falten razonamientos pragmáticos o consecuencialistas, atentos a los efectos politicos desfavorables de la obligatoriedad del voto o de su inscripción en una normativa constitucional. Esta posición fue defendida por Martín C. Martínez, activo convencional del Partido Nacional, quien insistiera en los riesgos contingentes de la obligatoriedad del voto, en la falta de experiencia suficiente en el ámbito nacional e internacional sobre los efectos políticos de dicha normativa. Con todo, Martínez evitó alinearse en una "oposición doctrinaria" (DSHCNC, tomo II, p. 259-260), inclinándose por dejar librado el asunto, tal como lo hiciera algún otro convencional, a una ley ordinaria (DSHCNC, tomo II, p. 261).

El rechazo a la obligatoriedad del voto inspirado en tópicos liberales, particularmente centrados en convicciones normativas o de principio, encontró sus principales referentes en algunos constituyentes del Partido Nacional, quienes focalizaron sus argumentos en las libertades individuales y en la autonomía de los individuos frente a las interferencias del Estado o de mayorias legislativas. Entre las posturas mayormente consustanciadas con los principios fundantes del liberalismo moderno, se destaca la de Eduardo Rodriguez Larreta, convencional nacionalista, quien en una de sus intervenciones sostuvo:

Soy contrario al voto obligatorio, y soy contrario á él en teoria y en la práctica nacional (...). Empiezo por declarar, que tengo una repugnancia instintiva hacia todo aquello que tienda á limitar la libre autonomía del individuo. Tal vez seré un poco romántico, señor Presidente, en estos tiempos en que el Estado. nuevo monstruo proteiforme, empieza á invadir hasta los resortes más intimos de la actividad individual y vuelve á reproducir aquellas épocas antiguas en las cuales se tomaba el ciudadano desde la escuela y se le imponían normas obligatorias de conducta, no perdiéndosele de vista hasta que moria, siempre sujeto y siempre sometido á la voluntad predominante y absorbente del Estado. Poco a poco vamos volviendo á ese sistema perjudicial, á ese sistema antidemocrático, diré si se me permite la expresión. A ese sistema que tiende a reducir la acción libre del individuo, y á entregarlo á la voluntad prepotente del Estado, que no lo respeta ni en sus 
fueros más intimamente individuales (DSHCNC, tomo II, p. 270-271).

Para este convencional, la obligatoriedad del voto formaba parte de una ofensiva del Estado sobre los derechos individuales, constituyendo "imposiciones" tendientes a coartar "la libre autonomia" de los individuos (DSHCNC, tomo II, p. 261). A su juicio, la prescripción de la obligatoriedad del voto podia "dar lugar á esos excesos (...) que desde la Revolución Francesa (...) han contrariado el principio del sufragio universal" fundándose "en la doctrina de que el sufragio es una función y no un derecho." (DSHCNC, tomo II, p. 298). Combinando argumentos teóricos con referencias históricas, Rodriguez Larreta sostuvo que "lo primordial es el derecho; y desde el momento que el voto es un derecho, el voto no puede ser impuesto, sino que debe ser el fruto de la libre autonomía de los ciudadanos." (DSHCNC, tomo II, p. 273). Y si bien admitió que el Estado ya no podía restringirse a su rol de "juez y gendarme", dada su intervención en múltiples esferas de acción, lo que lo habria convertido en "una máquina de progreso avanzando constantemente", también argumentó que "de esto á admitir que el principio intervencionista se vaya extendiendo á todas las esferas de la actividad individual, (...) creo que hay una distancia que no debemos recorrer ligeramente." $Y$ abundando en estas posiciones, sostuvo:

Con la doctrina de que el sufragio no es un derecho, sino una función pública, es que mañana se podría justificar el que se arrebatara al pueblo sus derechos, bajo el pretexto que no sabía ejercer bien esa función pública, y que tal vez un cuerpo de elegidos desempeñaría mejor la grave misión que incumbe a los electores. (...) Seria un atentado, porque el voto es un derecho y no una función." (DSHCNC, tomo II, p. 271-272).

Al partir de la identidad entre el voto y el derecho individual, Eduardo Rodriguez Larreta sostuvo que debian ser los partidos quienes, mediante las campañas electorales, estimularan el sufragio y no apelando a la "coacción" de la ley. También se manifestó contrario a que se excluya de los empleos públicos a los ciudadanos que no desearan votar, ya que esta decisión debia ser fruto de la voluntad de los individuos. Por último, exaltó las virtudes del voto secreto, y criticó las ya referidas opiniones de Justino Jiménez de Aréchaga en favor del voto público y obligatorio, expresadas en su obra La libertad politica de 1884.

Ante la asimilación del voto a una libertad no interferida de los individuos y frente al tratamiento de la participación cívica como un instrumento al servicio de las preferencias personales, el ya citado Washington Beltrán respondió que "si el sufragio es un derecho exclusivo y absoluto del individuo", debe admitirse "que puede vender el voto". "Si es un derecho exclusivo -añadió- puede hacer lo que le plazca, y sin embargo, no puede vender el voto, porque es un derecho social, porque la sociedad se lo puede reglamentar, porque es un derecho que tiene el individuo en interés de la sociedad" (DSHCNC, tomo II, p. 273).

Otro convencional, Hugo Antuña, también arremetió contra los argumentos liberales de Rodríguez Larreta, sosteniendo que "el voto obligatorio no ofende la libertad de los ciudadanos, porque es claro que cada cual votará de acuerdo con sus legítimas convicciones. Y si se quiere asimilarlo a una carga, se tratará, en todo caso, de una carga impuesta por la convivencia social bajo determinada forma de gobierno" (DSHCNC, tomo II, p. 254).

Por su parte, Aureliano Rodríguez Larreta, veterano representante de las huestes "principistas" de comienzos de la década de 1870, integrante de la bancada del Partido Nacional en la Convención Constituyente, se sumó a las posiciones liberales, argumentando enérgicamente contra la obligatoriedad del voto en términos por demás categóricos:

El voto obligatorio es un atentado contra la libertad del votante. La ley no tiene derecho de obligar á los ciudadanos á votar (...). No: sufragio no es más que un derecho; nosotros tenemos el derecho de votar, pero no tenemos la obligación de votar. (...) El voto obligatorio es contrario á la libertad de los ciudadanos (DSHCNC, tomo II, p. 286-288) 
Por cierto que en los discursos de algunos convencionales se advierte una combinación de elementos republicanos y liberales. Tal es el caso de Horacio Maldonado, quien manifestara su preocupación por articular instituciones garantes de la libertad individual con prácticas que aseguren el pleno ejercicio de las libertades políticas, de modo de fortalecer la conformación electiva de los poderes públicos. No obstante, Maldonado consideró que el celo normativo por las libertades individuales debía reservarse "para cuando el Estado invada los resortes más intimos de la actividad de cada individuo; para cuando el Estado, desconociendo su verdadera misión, no sepa ver en cada hombre una fuerza individual que debe tener un libre desarrollo, sin perjuicio de lo que esa fuerza deba a la comunidad en que obra" (DSHCNC, tomo II, p. 296). De ahi que este portavoz de un republicanismo liberal no viera con malos ojos la obligación de los ciudadanos para "que elijan las personas que consideren más dignas de constituir los diversos órganos de autoridad." "Esa obligación -sostuvo- no es ningún sacrificio moral, ni material: antes al contrario, es una obligación que todo ciudadano acepta sin repugnancia alguna", confiriendo "más realidad y fuerza al gobierno representativo, con la intervención del mayor número posible de ciudadanos en su formación." Y sin dejar de reivindicar los derechos individuales, Maldonado advirtió que la democracia podria estar en peligro cuando los ciudadanos "no saben cumplir con sus deberes cívicos; cuando una indiferencia criminal por la cosa pública invade a un conjunto enorme de ciudadanos; cuando sólo acuden a las urnas un centenar de animosos; cuando los Poderes Públicos no son expresión de la voluntad popular, por no haber intervenido esta última en la formación de aquéllos" (DSHCNC, tomo II, p. 296 - 297).

Finalmente, las mayorias para la aprobación de la enmienda sobre el voto obligatorio no fueron alcanzadas y este no fue incluido en el texto de la reforma constitucional. Habrá que esperar hasta 1934 para que la obligatoriedad del voto se incorpore a la Constitución Nacional, cuando se harán sentir argumentos tendientes más bien a combinar derechos y deberes ciudadanos, en una época en que reinará un ambiente favorable a las lógicas políticas plebiscitarias, en desmedro de los preceptos liberales y republicanos, altamente celebrados en la génesis histórica de la democracia uruguaya y de las democracias de primera generación.

El sufragio obligatorio fue aprobado por la Convención Nacional Constituyente del año 1933. electa tras el golpe de Estado de ese año, en el marco de lo que dio en llamarse una "revolución conservadora", sin mayores discusiones sobre el punto. Quien propusiera esta enmienda, Anibal Uriarte, representante del Partido Nacional insistió, en particular, en que la obligatoriedad del voto iba a facilitar "la acción democrática del pueblo" (DSCNC, 1934, p. 170). Tras pasar revista a los clásicos argumentos del republicanismo local sobre la validez del voto obligatorio, Uriarte destacó su finalidad contraria a la abstención electoral y acentuó la importancia de establecer sanciones a quienes no concurriesen a votar. Esta perspectiva vino a acentuar asi el "signo igualitario" del sufragio en las "nuevas democracias", junto con su maximización contra una concurrencia minoritaria a las urnas (DSCNC, 1934, p. 170).

\section{Consideraciones finales}

El debate sobre la obligatoriedad del sufragio revela una serie de persistentes alineamientos en torno a una estructura de ideas y lenguajes emparentados con las clásicas teorias republicanas y liberales de la ciudadanía. Se trata de un eje de discusiones en torno a diversos aspectos relevantes de la tópica ciudadana y del proceso fundacional de la democracia uruguaya, llamado a adquirir particular significación práctica en las discusiones de la Convención Nacional Constituyente de 1916-1917, en la que vendrán a perfilarse los arreglos institucionales básicos de una democracia poliárquica en el Uruguay.

Los argumentos a favor del voto obligatorio, ya provengan del último tercio del siglo XIX, ya refieran a los debates constitucionales de 1917 , sintonizan con una visión republicana de la vida política y ciudadana, tendiente a jerarquizar las 
obligaciones y responsabilidades cívicas de la ciudadanía, así como su relación intrínseca con los sentidos vinculantes de la política y con el pleno ejercicio del autogobierno colectivo. Junto a una fuerte reivindicación de los bienes políticos propios de una comunidad autogobernada, las voces republicanas domésticas esgrimieron un ideal de perfeccionamiento cívico, unido a un fuerte compromiso con el espíritu público y el activismo ciudadano, ya presentes en el patriciado fundacional y en las huestes de la política ilustrada o doctoral de fines del siglo XIX, llegando a impregnar el ambiente político del primer batllismo, tal como se manifestara en sus empatías hacia las libertades políticas y a los protagonismos ciudadanos en la vida pública (CAETANO, 2011, p. 73-74).

Por su parte, las corrientes contrarias a la obligatoriedad del voto pondrán énfasis, en buena lógica liberal, en la pertenencia del sufragio a la órbita de los derechos individuales y en la autonomía electiva de los individuos, en desmedro de su consideración como un deber político inscripto en la norma o en las disposiciones virtuosas de los ciudadanos. A raíz de la discusión del voto obligatorio, las posturas liberales vinieron a articular una concepción negativa de la libertad, sensible a una autonomía individual preservada de interferencias políticas que resulten incompatibles con su integridad moral. Los temores ante la injerencia estatal en la vida de los individuos operaron como un telón de fondo de los argumentos liberales esgrimidos contra la obligatoriedad del sufragio, orientados a preservar la independencia individual frente a la soberanía de la política, a proteger, si se quiere, la libre elección de formas de vida frente a los valores participativos o perfeccionistas del republicanismo cívico.

En suma, la tensión entre la idea republicana de una comunidad ciudadana autogobernada y el individuo autónomo preconizado por el liberalismo atravesó un largo debate sobre el sufragio y la democracia en el Uruguay, de fuertes implicancias prácticas y políticas. Mientras de un lado se puso empeño en resaltar los alcances generales de la politica y sus correspondientes obligaciones cívicas, del otro se buscó preservar al individuo y sus derechos de las injerencias prescriptivas de la política o de un ethos civico-republicano.

Pese a las acumulaciones doctrinarias y discursivas de las sucesivas camadas del republicanismo criollo, el voto obligatorio no fue recogido en la carta constitucional plebiscitada en 1918, donde prevalecieron las posturas liberales, acompañadas de algunos razonamientos o juicios de conveniencia política. La obligatoriedad del sufragio se incorporará finalmente a la Constitución de 1934, aprobada bajo un gobierno surgido de un golpe dictatorial, al calor de algunas corrientes distanciadas de las vertientes republicanas decimonónicas, reactivadas en la encrucijada constitucional de 1917.

A su vez, la reglamentación del voto obligatorio y su aplicación efectiva tuvo lugar recién en 1971, cuando una legislatura envuelta en fuertes turbulencias políticas decidió implantarlo, acaso en función de ciertos cálculos políticos o estratégicos, cuando ya pocos recordaban los argumentos de moralidad republicana que, desde el último tercio XIX y principios del siglo $X X$, se esgrimieran en su favor. De todas formas, la herencia republicana quizás se haya hecho sentir, de alguna manera, en dicha reglamentación, la cual estableció los mecanismos más severos de control y sanción del incumplimiento del voto en el contexto regional, rindiendo de algún modo tributo al espíritu pro-político y republicano inscripto en la tradición política nacional.

\section{Referências}

AGUILAR, José Antonio; ROJAS, Rafael (coord.). El republicanismo en Hispanoamérica. Mexico: Fondo de Cultura Económica, 2002

ARENDT. Hannah. La condición humana. Barcelona: Paidós, 1993.

AUDIER, Serge. Les théories de la république. Paris: La Découverte, 2004.

BRUGGER, Bill. Republican theory in political thought: virtuous or virtual? New York: St. Martin's Press, 1999. https://doi.org/10.2307/2586219

CAETANO, Gerardo. La República Batllista. Montevideo: EBO, 2011. 
CAETANO, Gerardo. La República conservadora: 19161929. Montevideo: Editorial Fin de Siglo, 1989. t. 1.

CAETANO, Gerardo; RILLA, José. Los partidos politicos uruguayos en el siglo XX. In: NAHUM, Benjamin (dir.). El Uruguay del siglo XX. Montevideo: EBO - ICP, 2004. (La Política, t. 2). p. 15-64. https://doi. org/10.18234/secuencia.voi32.502

CAETANO, Gerardo; RILLA, José; PÉREZ, Romeo. La partidocracia uruguaya: historia y teoria de la centralidad de los partidos políticos. Cuadernos del CLAEH, Montevideo, n. 44, p. 37-62, 1987.

DERECHO Constitucional. Montevideo: Tipografía Escuela Nacional de Artes y Oficios, 1884.

DOMĖNECH, Antoni. Democracia, virtud y propiedad. In: ARTETA, Aurelio; GARCIA GUITIÁN, Elena; MÁIZ, Ramón (ed.). Teoría política: poder, moral, democracia. Madrid: Alianza, 2003. p. 270-315.

DSCNC (Diario de Sesiones de la Convención Nacional Constituyente), 1934.

DSHCNC (Diario de Sesiones de la Honorable Convención Nacional Constituyente), 1916-1917. 4 t.

EL SIGLO, 30 de agosto de 1872.

FILGUEIRA, Fernando. Un Estado social centenario: el crecimiento hasta el limite del Estado social batllista. In: FILGUEIRA, Carlos; FILGUEIRA, Fernando. El largo adiós al país modelo: políticas sociales y pobreza en el Uruguay. Montevideo: Arca/Kellogg Institute, 1994. https://doi.org/10.20983/noesis.2013.2.2

GALLARDO, Javier. Entre la república y la democracia: Justino Jiménez de Aréchaga. Revista Uruguaya de Ciencia Politica, Montevideo, v. 27, n. 1, p. 65-83, 2018. https://doi.org/10.26851/rucp. 27.3

GALLARDO, Javier. Las ideas republicanas en los origenes de la democracia uruguaya. Revista Iberoamericana de Filosofía, Politica y Humanidades, Sevilla, v. 5. n. 9. p. 3-44, 2003.

GALLARDO, Javier. La "religión" republicana y la politica uruguaya a fines del siglo XIX. In: GIOSCIA, Laura (comp.). Ciudadanía en tránsito: perfiles para el debate. Montevideo: EBO - ICP, 2001. p. 39-68.

GALLARDO, Javier. Republicanismo, ciudadanía y política en el Uruguay. In: CHERESKY, Isidoro (comp.). Ciudadania, sociedad civil y participación politica. Buenos Aires: Miño y Dávila, 2006. p. 443-478.

HAAKONSEN, Knud. Republicanism. In: GOODIN, Robert; PETTIT, Philip (ed.). A companion to contemporary political philosophy. Cambridge: Blackwell, 1995.

HABERMAS, Jürgen. Facticidad y validez. Madrid: Trotta, 1998.

JIMÉNEZ DE ARÉCHAGA, Justino. La libertad política: fragmentos de un curso de derecho constitucional. [S. l.]: Nabu, 2012.

KYMLICKA, Will. Ciudadanía multicultural. Barcelona: Paidós, 1996.
LANZARO, Jorge. Continuidad y cambios en una vieja democracia de partidos: Uruguay 1910-2010. Cuadernos del Claeh, Montevideo, v. 33, n. 100, p. 37-77, 2012. https://doi.org/10.1590/s0104$\underline{62762013000200001}$

LANZARO, Jorge. Fundamentos de la democracia pluralista y estructura política del estado en el Uruguay del siglo XX. Revista Uruguaya de Ciencia Politica, Montevideo, v. 14, n.1, p. 103-155, 2003. https:// doi.org/10.26851/rucp. 27.4

LÓPEZ BURIAN, Camilo. Republicanos y liberales: el debate sobre la ciudadania en el nacimiento de la democracia uruguaya (1916-1917). 2009. Tesis (Maestría en Ciencia Política) - Facultad de Ciencias Sociales, Universidad de la República, Montevideo, 2009.

MILL, John Stuart. Sobre la libertad. Madrid: Alianza, 1970.

MILLER, David. Ciudadanía y pluralismo. La Politica, Barcelona, n. 3, p. 69-92, 1997.

NINO, Carlos. Una teoría para la democracia. Buenos Aires: Siglo XXI Editores, 2013.

ODDONE, Juan. La formación del Uruguay moderno: la inmigración y el desarrollo económico-social. Buenos Aires: EUDEBA, 1966. https://doi. org/10.2307/2511843

OVEJERO, Felix; MARTI José Luis; GARGARELLA, Roberto (ed.). Nuevas ideas republicanas: autogobierno y libertad. Barcelona: Paidós, 2004.

PEÑA, Javier. La ciudadanía. In: ARTETA, Aurelio; GARCÍA GUITIÁN, Elena; MÁIZ, Ramón (ed.). Teoría política: poder, moral, democracia. Madrid: Alianza, 2003. p. 215-245.

PETTIT, Philip. Republicanismo: una teoría sobre la libertad y el gobierno. Barcelona: Paidós, 1999. https://doi.org/10.1093/0198296428.001.0001

PIVEL DEVOTO, Juan. Historia de los partidos politicos en Uruguay. Montevideo: Cámara de Representantes, 1994. $2 \mathrm{~V}$.

POCOCK, John. The concept of language and the métier d'historien. In: PADGEN, Anthony (ed.). The language of politics in the early modern Europe. Cambridge: Cambridge University Press, 1987. p. 19-38. https://doi.org/10.1017/cbog780511521447.002

QUENTIN, Skinner. Lenguaje, politica e historia. Buenos Aires: Universidad Nacional de Quilmes, 2007.

RAWLS, John. El liberalismo político. Barcelona: Crítica, 2004.

REAL DE AZÚA, Carlos. Uruguay, ¿una sociedad amortiguadora? Montevideo: EBO, 2000.

ROJAS, Rafael. Las repúblicas de aire: utopia y desencanto en la revolución de Hispanoamérica. Mexico: Taurus, 2009.

RORTY, Richard et al. La filosofia en la historia: ensayos de historiografía de la filosofía. Barcelona: Paidós, 1990. 
TERCHECK, Ronald. Republican paradoxes and liberal anxieties: retrieving neglected fragments of political theory. New York: Rowman \& Littlefield Publishers, 1997. https://doi.org/10.1017/ s0953820800006178

\section{Javier Gallardo}

Doutor em Ciência Política (Universidade Cándido Méndes IUPERJ, Rio de Janeiro, Brasil). Professor Titular do Instituto de Ciência Política - Faculdade de Ciências Sociais - Universidade da República, Uruguai. Pesquisador Ativo Nivel 1 do Sistema Nacional de Pesquisadores (SNI) da Agência Nacional de Pesquisa e Inovação (ANII) do Uruguai.

\section{Camilo López Burian}

Doutor em Ciência Política (Universidade da República, Uruguai). Professor Adjunto do Instituto de Ciência Política - Faculdade de Ciências Sociais - Universidade da República, Uruguai. Pesquisador Ativo Nivel 1 do Sistema Nacional de Pesquisadores (SNI) da Agência Nacional de Pesquisa e Inovação (ANII) do Uruguai.

\section{Dirección Postal:}

Camilo López Burian

Instituto de Ciencia Política de la Facultad de Ciencias Sociales de la Universidad de la República.

Constituyente 1502. Piso 6, Escritorio 615, Montevideo.

CP 11200, Uruguay. 